\title{
O Popol Wuj na contemporânea luta indígena Mesoamericana
}

Lia Pinheiro Barbosa

RESUMO: Escrito no século XVI, o livro sagrado Popol Wuj é parte constitutiva das obras que compõem a historiografia colonial da tradição indígena maia e considerado a obra mestra da literatura indígena mesoamericana. No presente artigo, apresentar-se-á seu fundamento cosmogônico e, sobretudo, o legado histórico, estético e político do Popol Wuj, nas lutas indígenas mesoamericanas, em nossa contemporaneidade e, em particular, na Guatemala e no México.

PALAVRAS-CHAVE: Popol Wuj. Mesoamérica. Povos Indígenas. Legado. Práxis política.

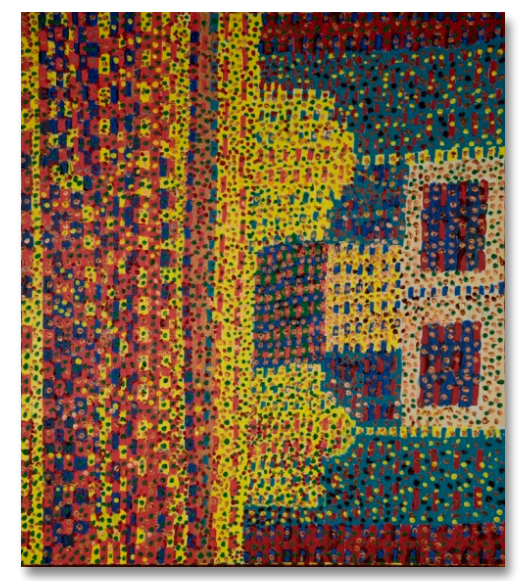

\section{The Popol Wuj in the contemporary Mesoamerican indigenous struggle}

\section{Lia Pinheiro Barbosa}

Socióloga pela Universidade Federal do Ceará (UFC) e Doutora em Estudos Latino-Americanos pela Universidade Nacional Autônoma do México (UNAM). Professora do Programa de Pós-Graduação em Sociologia e do Mestrado Acadêmico Intercampi em Educação e Ensino, ambos da Universidade Estadual do Ceará (UECE). Pesquisadora do CLACSO.

E-mail: lia.barbosa@uece.br.
ABSTRACT: Written in the 16th century, the sacred book Popol Wuj is a constitutive part of the works that make up the colonial historiography of the Mayan indigenous tradition and is considered the masterpiece of Mesoamerican indigenous literature. This article will present its cosmogonic foundation and, above all, the historical, aesthetic and political legacy of Popol Wuj in contemporary mesoamerican indigenous struggles, particularly in Guatemala and Mexico.

KEYWORDS: Popol Wuj. Mesoamerica. Indigenous Peoples. Legacy. Political Praxis.

RECEBIDO EM: 21/04/2019 Aprovado EM: 28/07/2019 


\section{Introdução}

Durante vários séculos, os manuscritos em línguas maias e caracteres latinos permaneceram ignorados em arquivos históricos de bibliotecas e museus da América e da Europa. Somente a partir de meados do século XIX, graças ao labor investigativo de pesquisadores interessados na história mesoamericana, esses escritos foram redescobertos e a cultura da antiga civilização maia pré-hispânica desvelou-se ante o olhar daqueles interessados em conhecer os segredos e a trajetória histórico-cultural dessa civilização. Durante o século XX, esses escritos foram traduzidos e difundidos, o que nos permitiu o acesso a essas fontes primárias da cultura mesoamericana.

A antologia dos escritos maias constitui uma das mais importantes expressões do pensamento, da capacidade literária e astronômica, do desenvolto conhecimento científico, bem como da organização da vida social, espiritual e política dos povos maias antes da conquista espanhola. Ao lado das centenas de inscrições hieroglíficas das pirâmides e dos templos das antigas cidades maias e dos códices maias - Códice de Dresde, Códice de Madri, Códice de Paris e Códice Grolier ${ }^{1}$-, os escritos pré-hispânicos tornaram-se fonte primária fundamental da historiografia colonial, sobretudo para conhecermos a civilização maia prévia à conquista e à colonização espanhola.

Existem diferentes traduções e estudos críticos que dão conta de recuperar, sistematizar e analisar criticamente os aportes da civilização maia ao conhecimento universal acerca de distintas áreas, tais como a matemática, a astronomia, a arquitetura, a filosofia, a medicina, a agricultura, entre outras, no sentido de reconhecê-las como patrimônio histórico-cultural. Para além do reconhecimento dessa longeva cultura, identificamos seu legado histórico entre as diferentes etnias de tronco maia e, especialmente, nas lutas indígenas contemporâneas da região mesoamericana.

1 Em 1562, o bispo mexicano Diego de Landa queimou todos os livros maias escritos antes da invasão espanhola, conhecidos como códices maias. Apenas estes quatro se salvaram. 
No presente artigo, visamos a uma aproximação com o legado dos escritos maias, em particular, com o livro sagrado Popol Wuj, com o intuito de apresentar ao leitor e à leitora os fundamentos cosmogônicos desse documento etnohistórico e a sua incidência estética e política na práxis de alguns movimentos indígenas. Para tanto, organizamos o artigo em três partes: a primeira se destina a uma apresentação sintética dos principais escritos maias pré-hispânicos; a segunda adentra ao contexto da obra Popol Wuj e seus fundamentos cosmogônicos e filosóficos; e, por fim, a terceira analisa o legado dessa obra na história recente da região mesoamericana, notadamente na práxis política de alguns movimentos indígenas do México e da Guatemala.

\section{Os escritos maias pré-hispânicos}

uma vez descoberta, reconhecemos a antologia dos escritos maias como fonte primária fundamental da historiografia dos povos pré-hispânicos, notadamente na investigação das tradições religiosas, da organização da vida social e das matrizes filosóficas da cosmogonia e da cosmovisão da civilização maia.

A civilização maia é conformada por um conjunto de etnias, ${ }^{2}$ que possuem diferentes línguas, trajetórias históricas e costumes. Entretanto, todas elas compartilham determinadas características que nos permitem considerá-las como uma só cultura. O desenvolvimento histórico pré-hispânico da civilização maia compreende, aproximadamente, do século XVIII a.C. ao século XVI d.C., isto é, cerca de 3.400 anos (DE LA GARZA, 2012). Atualmente, integram o território maia a Guatemala, Belize, uma parte de Honduras e El Salvador, além dos estados de Yucatán, Campeche, Quintana Roo, Tabasco e parte de Chiapas, no México.

Organizamos os principais escritos maias ${ }^{3}$ pré-hispânicos, conforme o quadro abaixo:

2 Quichés, cakchiqueles, tzutuhiles, tzeltales, tojolabales, tzotziles, mames, ch'oles, entre outros.

3 Optamos por colocar os nomes em espanhol em caso de que os leitores tenham interesse em procurá-los, sobretudo por desconhecer a existência de traduções ao português. 
Quadro 1 - Relação dos principais livros maias

\begin{tabular}{|c|c|}
\hline Origem dos escritos & Relação dos livros maias \\
\hline Maias-Yucatecos & $\begin{array}{l}\text { - Libros de Chilam Balam } \\
\text { - Cantares de Dzitbalché } \\
\text { - Códice de Calkiní } \\
\text { - Códice Pérez } \\
\text { - Crónica de Maní } \\
\text { - Crónica de Yaxkukul } \\
\text { - Crónicas de los Xiú } \\
\text { - Documentos de tierras de Sotuta } \\
\text { - Documentos de Tabí } \\
\text { - Libros del judio } \\
\text { - Ritual de los Bacabes } \\
\text { - Títulos de Ebtún }\end{array}$ \\
\hline Chontales & - Papeles de Paxbolon-Maldonado \\
\hline Quichés & $\begin{array}{l}\text { - Popol Vuh } \\
\text { - Rabinal Achí } \\
\text { - Título de Totonicapán } \\
\text { - Título de Yax, Título de Cristóbal Ramírez y Título de } \\
\text { Pedro Velasco } \\
\text { - Memorial de la Conquista y Título de Totonicapán } \\
\text { - Título Tamub } \\
\text { - Título C'oyoi } \\
\text { - Títulos Nijaib } \\
\text { - Título del Ajpop Huitzitzil Tzunún } \\
\text { - Título de los índios de Santa Clara la Laguna } \\
\text { - Título de los señores de Sacapulas } \\
\text { - Zacxicocxol, Baile de la Conquista } \\
\text { - Papel del origen de los señores ou Título Zapotitlán }\end{array}$ \\
\hline Cakchiqueles & $\begin{array}{l}\text { - Anales de los cakchiqueles } \\
\text { - Historias de los Xpantzay } \\
\text { - Transunto de los títulos de tierras de Tecpán, } \\
\text { Guatemala } \\
\text { - Título Chajoma } \\
\text { - Título de Alotenango }\end{array}$ \\
\hline Tzutuhiles & $\begin{array}{l}\text { - Relación de los caciques y principales del Pueblo de } \\
\text { Atitlán ou Relación Tzutuhil } \\
\text { - Título de San Bartolomé de la Costilla }\end{array}$ \\
\hline Mames & $\begin{array}{l}\text { - Título de San Pedro Necta } \\
\text { - Título de Ostuncalco y Chiquirichapa }\end{array}$ \\
\hline Pokomichís & - Título de San Cristóbal Verapaz (Cagcoh) \\
\hline
\end{tabular}

Fonte: De La Garza (2012). ${ }^{4}$

4 Para a elaboração do quadro 1, tomamos por base a relação dos principais livros maias elaborada pela pesquisadora Mercedes De La Garza (2012) que, em sua pesquisa, apresenta uma síntese de cada um deles, além de indicar fontes historiográficas e documentais para aqueles que se interessarem em aprofundar cada uma das obras. 
Conforme Slaviero $(2004,2007)$, os escritos pré-hispânicos apresentam uma peculiar concepção do cosmos bem como concepções religiosas, além da preocupação com os registros históricos, sobretudo de seus conhecimentos e logros científicos que superam, em muitos aspectos, aos de outras culturas antigas do mundo. Por exemplo, os maias inventaram a matemática com o sistema vigesimal, o valor posicional dos signos matemáticos e do zero como posição vazia (mais ou menos 1.000 anos antes dos hindus), mediram com precisão o movimento das estrelas, os ciclos lunar, solar e de Vênus, o que lhes permitiu prever eclipses (DE LA GARZA, 2012).

Os antigos maias organizavam ciclos de tempo como kin (dia), winaq (20 dias), tun (360 dias), katún (7.200 dias) e baktún (144.000 dias), cuja contagem se iniciava no dia da criação do mundo. O primeiro kin na contagem do tempo maia corresponde, no calendário gregoriano, ao dia 11 de agosto de 3114 a.C. (ALVARADO et. al., 2013). À diferença do calendário gregoriano, os maias criaram um complexo sistema de datar, denominado "sistema calendári$\mathrm{co}^{\prime \prime}$, isto é, usavam diversos calendários, sempre sincronizados entre si e de cada um se obtinha determinada informação sobre o tempo. O sistema calendárico maia está composto por três contagens do tempo (ALVARADO et. al., 2013), a saber:

- A cuenta larga ou série inicial: baseada em ciclos - calendários solares, lunares, rituais, entre outros - e usada para o registro do tempo no calendário pré-hispânico. Também era utilizada para o registro ou previsão de determinados acontecimentos na história e, portanto, podia indicar um kin preciso no passado ou no futuro, seja próximo ou mais longínquo (ALVARADO et. al. , 2013). Outro sistema usado desde o período clássico até a conquista é o chamado rueda de los katunes (período de 256 dias) ou u kablay katunob (cuenta corta). ${ }^{5}$

- O Haab': corresponde ao calendário solar de 365 dias, que os maias identificaram, com exatidão, observando os ciclos ou movimentos do sol. Esse calendário era fundamental para organizar a agricultura.

5 Para um aprofundamento acerca da organização dos calendários maia, ver De La Garza (2012). 
- O calendário sagrado Cholq'ij: composto por 260 dias, ele está relacionado com o ciclo da gestação humana (o tempo necessário para que o feto se desenvolva no ventre) e é considerado sagrado, porque permite controlar e analisar as diversas energias presentes em cada dia e decidir quais são os períodos mais propícios para realizar diferentes atividades, desde cerimônias religiosas, rituais de benção para o plantio, a caça ou a criação de animais, construção de edifícios ou casas, aplicação da justiça, tomar decisões, etc.

Na cultura maia, os diferentes calendários possuem uma cosmogonia que determina, de maneira benéfica ou maléfica, os destinos dos natalícios, das ações individuais e coletivas, dos rituais sagrados, dos matrimônios, das atividades agrícolas, das festas, dentre outras. Eles sempre eram previamente consultados para que não se corresse o risco do fracasso, em caso de que o evento coincidisse com um dia considerado maléfico (MARIÓN, 1994; 1999; DE LA GARZA, 2012). Eram os sacerdotes os que dominavam o conhecimento do sistema calendárico, portanto, os encarregados de definir as datas mais propícias para quaisquer atividades, no sentido de garantir seu devido êxito.

O conhecimento do cosmos, dos astros e da organização do tempo associava-se ao fato dos maias acreditarem em uma concepção cíclica da história, decorrente, sobretudo, do aparente movimento cíclico do Sol - K'inich Ahau -, considerado eixo da vida e da criação maia, a deidade celeste identificada como suprema criadora, Itzamná (DE LA GARZA, 2012). Entretanto, esse conhecimento não se tratava de um domínio mítico ou unicamente da ordem do sagrado, mas de uma gnose vinculada a um espírito antropocêntrico, de preocupação profunda com o destino do ser humano, isto é, de seu próprio porvir como civilização. Portanto, os escritos maias nos revelam a inquietude permanente com o devir humano, com um planejamento do seu futuro a partir do vivido em seu passado. Assim, a antologia dos textos pré-hispânicos são o registro escrito da memória histórica de uma civilização - a civilização maia pré-hispânica - que foi determinante para a criação: 


\begin{abstract}
[...] dos livros maias pós-hispânicos, e tanto é assim que são precisamente estas obras as que nos proporcionaram a informação básica, corroborando os dados arqueológicos e epigráficos, para nos aproximar à aproximação dos conceitos maias (DE LA GARZA, 2012, p. 62 - tradução nossa).
\end{abstract}

A articulação entre uma abordagem espiritual associada ao conhecimento científico expressa a complexidade do pensamento maia, transmitido de geração a geração, a partir das tradições orais, de códigos antigos que revelam a herança cultural e espiritual de seus antepassados, de suas normas de convívio social, de sua relação com o mundo terreno e divino, de todo um constructo sociocultural milenar que articula uma racionalidade sofisticada na compreensão do universo em sua totalidade, com o fim de melhorar a vida do ser humano em plena integração com o cosmos e a natureza.

Enquanto herança histórica, cada livro maia constituía um popol vuh - livro sagrado da comunidade -, que continha os mitos e os rituais, as linhagens e os parentescos, o patrimônio material, entre outros dados históricos considerados de relevância sociocultural para a comunidade e que eram anotados secularmente por sacerdotes ou conhecedores dos códigos antigos. Esses livros eram cuidadosamente guardados por alguma família reconhecida na comunidade e herdados de pais para filhos. A leitura em voz alta pelos sacerdotes era o método de transmissão de seu conteúdo para as comunidades.

Sendo assim, De La Garza (2012) organiza a antologia dos escritos maias em:

- Livros sagrados da comunidade: não possuem necessariamente uma unidade temática, uma vez que incorporam tradições espirituais e históricas, da cosmogonia maia, da literatura mítica, profética e ritual, da literatura médica, astronômica e do sistema calendárico. Há aqueles que são recopilações de fragmentos escritos por diferentes autores e épocas, além daqueles que constituem uma obra unitária, provavelmente escrita por um único autor. Entre esses 
livros, destacam-se: Libros de Chilam Balam, Cantares de Dzitbalché, Ritual de los Bacabes, Popol Wuj, Rabinal Achí e Anales de los cakchiqueles.

- Textos histórico-legais: escritos com o objetivo de preservar e comprovar a herança material dos maias, como títulos de propriedade, tratados de terras, títulos de herança, de méritos e serviços, entre outros. Esses documentos foram redigidos por famílias nobres e apresentados perante autoridades coloniais, sobretudo em ocasiões de litígio de terras ou cobrança de tributos, com o fim de requerer direitos, seja de caráter individual-familiar ou comunitário. Entre esses textos, se destacam: Título de San Cristóbal Verapaz (Cagcoh), Historias de los Xpantzay, Título de Yax, Título de Cristóbal Ramírez y Título de Pedro Velasco e Códice de Calkiní.

No presente artigo, adentraremos em um dos livros sagrados, o Popol Wuj.

\section{O contexto e os fundamentos da obra Popol Wuj}

O Popol Wuj é uma obra unitária escrita no século XVI e que nos apresenta detalhes sobre o mito criador do mundo, dos homens, das mulheres, da relação entre masculino e feminino, dos animais, das ideias cosmogônicas e das antigas tradições dos povos k'iche', bem como sobre a organização do calendário maia e a cronologia dos seus reis até o ano de 1500. Como parte constitutiva da chamada historiografia colonial da tradição maia, consideramos o Popol Wuj a obra mestra da literatura e do pensamento maia, cujo legado se expressa por meio de uma oralidade e de uma estética poética que preservaram a memoria de fatos históricos dos povos maias da América Central e da Mesoamérica (COBIÁN, 1999; SANTOS; VALVERDE, 2003; SLAVIERO, 2007).

Os maias realizavam o registro dos acontecimentos históricos mediante a escrita pictográfica e fonética, uma tradição historiográfica que vemos presente no Popol Wuj. Conforme Recinos (1982), esse livro é uma reelaboração alfabética de um antigo código hieroglífico e pictográfico que permaneceu em poder de Oxib, 
Kej e B'eleje T'zi', chamados de Ajpop'ib' K'iché (os governantes), os quais representavam a duodécima geração de reis até a chegada dos espanhóis, no século XVI. Com o assassinato dos Ajpop'íb' K'iché pelos espanhóis, os caciques Tecum e Tepepul se tornaram os guardiães dos códigos. O autor considera que este primeiro documento, desaparecido, constitui um protótipo que serviu de base para a escritura do Popol Wuj em língua k'iché, em meados do século XVI, e que foi traduzido para o espanhol, entre 1554 - 1558.

A escrita do Popol Wuj com caracteres latinos, mas em língua k'iche', constituiu uma estratégia de resistência dos maias frente aos invasores espanhóis no século XVI, sobretudo para conservar na memória os códigos e símbolos de sua cultura. Conforme o antropólogo k'iché Enrique Sam Colop (2008), a tradução do Popol Wuj aconteceu em duas fases: primeiro ao idioma k'iche', com o alfabeto contemporâneo, para que os povos k'iches' tivessem acesso à leitura em seu idioma, e, posteriormente, ao espanhol. No trânsito entre mitologia e história, o Popol Wuj nos apresenta uma regressão literária que faz dele um livro não linear. Além disso, possui metonímias, metáforas e outras figuras literárias que tornam complexa a interpretação do manuscrito, incorrendo em imprecisões ou erros em algumas traduções. Para o autor, a maioria das traduções enfocou muito mais no conteúdo do Popol Wuj, desconsiderando ou esquecendo o estilo literário em que foi escrito, uma combinação de verso e prosa.

Conforme Slaviero (2007), embora o Popol Wuj tenha sido escrito em formato alfabético, podemos identificar a estrutura narrativa de origem pré-hispânica, caracterizada por partículas de uso retórico que demarcam a transição entre os episódios descritos no livro. A retórica do Popol Wuj combina elementos textuais e da tradição oral, característicos da escrita indígena. Portanto, era um texto escrito para ser recitado ou cantado em cerimônias (às vezes, clandestinas) das comunidades.

Nas traduções do Popol Wuj que conhecemos, há algumas hipóteses relacionadas à autoria do escrito, entre elas, a de que o autor do manuscrito foi Diego Reinoso, um maia k'iche', levado da comunidade de Utatlán à Guatemala pelo bispo Marroquín, e que por lá aprendeu a escrever em castelhano (VILLACORTA; RODAS, 
1927 apud RECINOS, 1982). Entretanto, Recinos (1982) afirma que não há uma comprovação histórica de que Reinoso tenha sido o autor do livro, o que ainda torna desconhecidos a autoria e o paradeiro da obra original.

O manuscrito que deu origem ao Popol Wuj foi descoberto no início do século XVIII, no povoado de Santo Domingo Chichicastenango, pelo Padre Francisco Ximénez, frade da Ordem de Santo Domingo. Ximénez foi quem realizou a primeira transcrição do texto $k^{\prime}$ iche' e sua tradução ao castelhano, ${ }^{6}$ sob o nome de Histórias da origem dos índios desta província de Guatemala. Nesta tradução, ele considera o Popol Wuj como o livro das profecias e o oráculo dos reis e senhores (RECINOS, 1982). Atualmente, conhecemos o livro por Popol Wuj, Popol Buj, Popol Vul, Livro dos Conselhos, Livro Sagrado, Livro do Comum ou ainda Livro Nacional dos Quichés.

A tradução literal de Popol Wuj é "livro da comunidade" (RECINOS, 1982). A palavra popo é de origem maia e significa "reunião" ou "casa comum" e Popol na é a "casa da comunidade onde se reúnem para tratar de temas da república". Pop é um verbo k'iche' que significa "juntar, congregar, amontoar pessoas" e Popol se refere a algo pertencente ao comunal, ao nacional. Com base nessa matriz linguística, pudemos inferir que o Popol Wuj foi um livro de propriedade comum da comunidade e que talvez tenha sido interpretado pelo padre Ximénez como o Livro do Conselho.

O Popol Wuj está organizado em quatro partes, cada uma delas composta por capítulos que versam sobre a origem do cosmos, a criação do mundo e dos primeiros homens e mulheres, a criação dos animais e das plantas, além de elementos da espiritualidade ancestral - em particular, a relação entre os deuses criadores e os humanos - e das tradições populares, que são parte constitutiva da

6 Além da tradução de Ximenéz (1857), outras traduções do Popol Wuj foram realizadas, com destaque para os seguintes autores: Abate Brasseur de Bourbourg (1861), Noah Elieser Pohorilles (1913), Georges Raynaud (1925). Almaguer (2015) destaca as traduções realizadas por intelectuais maias, ao longo dos séculos XX e XXI, e o caráter descolonizador dessas traduções, sobretudo as de Adrián Inés Chávez (1979), Pakal B’alam Rodríguez Guaján (2007) e Luis Enrique Sam Colop (2008). 
história das principais nações dos povos originários que habitaram o território da Guatemala, após o declínio do Velho Império Maia. O Popol Wuj menciona as três ramas principais da família $k^{\prime} i c h e^{\prime}$ - os Cavec, os Nimhaib e os Ahau-Quichés (RECINOS, 1982) - bem como os nomes dos primeiros homens criados pelos deuses criadores: Balam-Quitzé, Balam-Acab, Mahucutah e Iqui-Balam, todos feitos do milho.

De La Garza (2012) considera o mito cosmogônico do Popol Wuj um dos mais completos e significativos entre os mitos mesoamericanos sobre a origem:

Eis aqui, pois, o princípio de quando se dispôs a fazer o homem, e quando se buscou o que deveria entrar na carne do homem. E disseram os Progenitores, os Criadores e os Formadores, que chamam Tepeu e Gucumatz: "Chegou o tempo do amanhecer, de que se termine a obra e que apareçam os que nos hão de sustentar e nutrir, os filhos esclarecidos, os vassalos civilizados; que apareça o homem, a humanidade sobre a superfície da terra". Assim disseram (RECINOS, 1982, p. 159 - tradução nossa).

O milho constitui o âmago do mito criador dos seres humanos, símbolo do nascimento da humanidade e que acompanhará a cosmogonia e a cosmovisão das comunidades maias até nossa história recente. No Popol Wuj, quatro animais (o gato do monte, o coiote, o corvo e a catorra) trazem o Echá - a comida - para o ritual da criação dos primeiros homens. Quando se trata do ser humano, o Echá se refere ao milho cozido e moído, que era a comida do índio americano e que foi considerada, pelos $k^{\prime} i c h e ' s$, a base para formar os primeiros homens (RECINOS, 1982). A propósito da transmutação do milho em carne e sangue que reveste e preenche os corpos humanos, vemos que:

E assim encontraram a comida e esta foi a que entrou na carne do homem criado, do homem formado: esta foi seu sangue, desta se fez o sangue do homem. Assim entrou o milho [na formação do homem] por obra dos Progenitores. [...] Depois, começaram a conversar acerca da criação e da formação de nossa primeira mãe e pai. Do milho amarelo 
e do milho branco se fez sua carne; da massa do milho se fizeram seus braços e as pernas dos homens. Unicamente massa de milho entrou na carne dos nossos pais, os quatro homens que foram criados. (RECINOS, 1982, p. 160 - 161 - tradução nossa).

O Popol Wuj tornou-se uma obra de referência no âmbito da historiografia mesoamericana, sobretudo como matriz interpretativa de algumas práticas ainda presentes na vida comunitária dos povos maias e de fenômenos socioculturais e políticos de nosso tempo histórico. Enquanto documento etnohistórico, ele cobra vigência por interpelar interpretações colonialistas que categorizam aos povos originários como desprovidos de passado ou de uma história social própria, portanto, recupera a memória histórica, sobretudo como estratégia de descolonização e reapropriação das tradições orais, do conhecimento ancestral e da identidade cultural maia.

Na história contemporânea da América Latina, podemos identificar a presença do Popol Wuj e de outros referentes das cosmovisões que fundamentam as filosofias dos povos originários da região. Essa presença na narrativa política da luta indígena das regiões centro-americana e mesoamericana nos demonstra que, apesar da violência epistêmica que acompanhou a colonização espanhola e da quase destruição absoluta dos livros maias pré-hispânicos, sobreviveram marcos onto-epistêmicos da cosmogonia e da cosmovisão maia que nutrem a subjetividade política da luta histórica travada por esses povos.

\section{O legado histórico, estético e político do Popol Wuj}

Observamos a transcendência do Popol Wuj na reconstrução e no fortalecimento da memória histórica dos povos maias, especialmente na Guatemala e no México. Os princípios éticos e filosóficos inscritos nesse livro são apropriados em uma perspectiva sociocultural, estética, educativa e política nesses países, mantendo-se vivos na memória política das comunidades maias e nos movimentos de resistência política da América Central e da região mesoamericana. 
Os mitos de origem são fundamentais na conformação de uma identidade cultural e política, materializando-se na narrativa da resistência articulada pelos movimentos indígenas. Nesse sentido, gostaríamos de apresentar aos leitores alguns exemplos ${ }^{7}$ expressivos da apropriação estética, política e educativo-pedagógica do Popol Wuj na história contemporânea, tais como feito pelo Zapatismo, no México, e pelo Movimento de Resistência PolíticoCultural Maia, na Guatemala.

Conformado por etnias maias, ${ }^{8}$ o Movimento Zapatista encontra-se em Chiapas, México, e é considerado um dos movimentos indígenas contemporâneos mais emblemáticos da resistência latino-americana. Desde a Insurgência Armada de 1994 e ao longo da consolidação do seu projeto político autonômico, o Exército Zapatista de Libertação Nacional (EZLN) recupera a dimensão epistêmica do Popol Wuj, nos múltiplos espaços de sua práxis educativo-política, com o objetivo de fortalecer a identidade maia, bem como os princípios políticos que sustentam a luta por dignidade, justiça, paz e autonomia (BARBOSA, 2015).

Desde sua aparição pública com o rosto coberto pelo passa-montanhas ou pelo paliacate, ${ }^{9}$ os zapatistas se assumem como os "sem rosto" e colocam em relevo a denúncia da condição histórica das populações originárias, a partir da conquista, na expropriação de seus territórios e na negação das suas cosmovisões, de seu pensamento e da matriz epistêmica de suas línguas, em um processo que evidencia a violência epistêmica e a subalternização dessas populações por séculos.

7 Esclarecemos que o artigo não pretende aprofundar os exemplos que serão apresentados, haja visto que nosso enfoque é evidenciar a recuperação do Popol Wuj em alguns documentos, comunicados, entre outras expressões políticas. Entretanto, ao longo do artigo, fazemos referência a outros estudos que aprofundam os movimentos citados.

8 Das etnias tzeltales, tzotziles, tojolabales, mames, zoques, ch'oles.

9 O paliacate é o lenço, normalmente com tecido colorido em tons vermelhos, utilizado para cobrir parcialmente o rosto e historicamente usado pelas trabalhadoras e trabalhadores do campo. Além de expressar uma identidade política, um símbolo de trabalho, luta e resistência, o passa-montanhas e o paliacate são usados para que seus rostos não sejam identificados por militares e paramilitares. 
Na Quarta Declaração da Selva Lacandona, ${ }^{10}$ há uma importante passagem inspirada no Popol Wuj, referente à noite e ao seu nascimento como movimento indígena durante a noite: "Nós nascemos da noite. Nela vivemos. Morreremos nela. Porém, a luz será manhã para os mais, para todos aqueles que choram a noite, para quem se nega o dia, para quem o presente é a morte, para quem está proibida a vida" (EZLN, 1996, [s.p.] - tradução nossa).

Na segunda parte do Popol Wuj, no capítulo que apresenta o nascimento dos gêmeos Hun-Hunahpú e Vucub-Hunahpú, filhos de Ixpiyacoc e Ixmucané, se afirma que os gêmeos nasceram durante a noite. Em uma nota de rodapé, há a seguinte explicação sobre o nascimento na noite: "Chi agabal, isto é, antes que houvesse sol, nem lua, nem houvesse sido criado o homem" (RECINOS, 1982, p. 105 - tradução nossa). Nessa mesma passagem do Popol Wuj, afirma-se que os gêmeos eram grandes sábios, de boa índole e bons costumes, dotados de um conhecimento profundo da arte; eram flautistas, cantores, pintores, escultores, joalheiros.

Vários documentos emitidos pelo EZLN reforçam a identidade sociocultural e política herdada do Popol Wuj, na reafirmação de seu nascimento durante a noite, "a longa noite dos 500 anos" (conforme escrito na Primeira Declaração da Selva Lacandona), em alusão aos cinco séculos de colonização de nosso continente. Ao recuperar sua essência maia, o EZLN reafirma também o posicionamento político de que os povos originários existem, desde muito antes da conquista e da formação do Estado-nação moderno ocidental, em nossa região. Eles existem dotados de uma cultura milenar, que abrange um conhecimento matemático, estético, literário, astronômico, das tradições filosóficas e históricas, um patrimônio cultural que foi solapado e destruído em grande parte pelos espanhóis, negado e subjugado nas relações coloniais que marcam a conquista espanhola e que se perpetuaram até os nossos dias.

Além das seis Declarações da Selva Lacandona, entre outros documentos emitidos pelo EZLN, observamos uma apropriação estética, pedagógica e política do Popol Wuj, a exemplo dos livros político-literários do Subcomandante Insurgente Marcos.

10 Desde o alçamento armado de 1994, o EZLN emitiu seis Declarações da Selva Lacadona, documentos políticos para tornar público seu posicionamento com relação à política mexicana. 
Antes de apresentarmos elementos do Livro do Conselho em alguns desses escritos, nos parece fundamental destacar que, ademais da menção aos deuses criadores, no preâmbulo do Popol Wuj, há uma referência central à "avó" e ao "avô", chamados Ixpiyacoc e Ixmucané. Na tradução de Recinos (1982), ambos são considerados os protetores nas histórias k'iche's e narradores de tudo que foi feito no princípio da vida e da história. Recinos (1982) destaca que Ixpiyacoc e Ixmucané derivam da palavra maia ixnuc, que significa velho ou velha, "equivalentes aos deuses mexicanos Cipactonal y Oxomoco, os sábios que segundo a lenda tolteca inventaram a astrología judiciária e compuseram a contagem dos tempos, ou seja, o calendário" (RECINOS, 1982, p. 77 - tradução nossa).

É notória a alusão a essa passagem do Popol Wuj, em um dos principais escritos do Subcomandante Insurgente Marcos, o livro Relatos do Velho Antônio. No campo discursivo e literário, o coração místico e epistêmico do Zapatismo está representado pelo Velho Antônio e seus contos, que são relatados nesse livro. Não sabemos, ao certo, se realmente o Velho Antônio existiu ou se representa a criação de um personagem literário para expressar a trajetória pessoal do Subcomandante, durante os anos da clandestinidade na Selva Lacandona e de suas aprendizagens com as comunidades maias e sua cosmovisão. ${ }^{11}$

Mito ou realidade, não há como nos aproximar do Zapatismo sem sermos apresentados ao livro Relatos do Velho Antônio e seus contos, que abrem caminho para adentrarmos na polissemia da cultura e da simbologia maias e conhecermos as interfaces do encontro de dois mundos, o indígena e o mestiço, ou, nas palavras de Navarro (2011), do mexicano com sua memória:

O diálogo do Sub Marcos com o Velho Antônio nos introduz a uma história que, sendo também nossa, nos é desconhecida por não ser a escrita pela pluma do vencedor, por estar

11 Jan de Vos (2002) afirma que o Velho Antônio existiu. Seu nome era José Antônio, um camponês que viveu na comunidade ch'ol de Huitupan e que participou da fundação das comunidades Emiliano Zapata e Tierra y Libertad, nos anos 70 do século XX. Amigo do Subcomandante Insurgente Marcos, era pai da Major Ana María, que foi companheira do Subcomandante por mais de dez anos. 
silenciada e desprezada até o último recanto da nossa geografia. É através dos mitos, das parábolas e lendas da cultura maia que o escrivão do texto se dispõe a aprender a escutar para logo aprender ensinando e lutando, fazendo-se um com os homens e mulheres de milho para ir ao seu resgate, rompendo as sombras e o silêncio, para nos narrar outra forma de luta e de resistência que nos aproxima a sua cosmovisão, uma das mais ricas da Mesoamérica. (NAVARRO, 2011, p. 05 - tradução nossa).

Na edição de 2011 do livro Relatos do Velho Antônio, dos 51 contos, encontramos pelo menos 11 que trazem referências diretas aos escritos do Popol Wuj, com destaque para os seguintes: $A$ história da noite e das estrelas; A história das nuvens e da chuva; A história das perguntas; A história das palavras; A história dos sonhos; A história do princípio e do fim; A história da medida da memória; A história de Hurakán e a palavra que como acordo nasce; A história do calendário; A história da noite; e, por último, A história da falsa luz, a pedra e o milho.

Há uma intrínseca relação entre o legado da cosmovisão e da cosmogonia maia, herdado do Popol Wuj, no campo simbólico, ideológico e político, e a conformação do EZLN. Em um comunicado de 13 de dezembro de 1994, o Subcomandante Insurgente Marcos narra a percepção do Velho Antônio com respeito aos guerrilheiros mestiços que chegaram à Selva Lacandona, localizada em Chiapas:

O velho Antônio sorri e a agrega: "Escutei falar de vocês. Nos vales dizem que são bandidos. Na minha comunidade estão inquietos porque podem andar por esses rumos". "E você acha que somos bandidos?", pergunto. O velho Antônio lança uma grande baforada de fumaça, tosse e nega com a cabeça. Eu me animo e faço outra pergunta: "E o que você acha que somos?". "Prefiro que tu me digas", responde o velho Antônio e fica olhando-me nos olhos. "É uma história muito longa", digo e começo a contar de quando Zapata e Villa e a revolução e a terra e a injustiça e a fome e a ignorância e a doença e a repressão e tudo. E termino com um "e então nós somos 
o Exército Zapatista de Libertação Nacional". Espero algum sinal no rosto do velho Antônio que não deixou de fitar-me durante minha fala. "Conta-me mais desse Zapata", disse depois de fumaça e tosse. Eu começo com Anenecuilco, sigo com o Plano de Ayala, a campanha militar, a organização dos povos, a traição de Chinameca. O velho Antônio segue fitando-me enquanto termino o relato. "Não foi assim", me diz. Eu faço um gesto de surpresa e só consigo balbuciar: "Não?". "Não", insiste o velho Antônio: "Eu vou te contar a verdadeira história do tal Zapata". Tirando tabaco e o papel para o pé duro, o velho Antônio inicia sua história que une e confunde tempos antigos e novos, tal e como se confudem e unem a fumaça do meu cachimbo e a do seu cigarro. "Há muitas histórias, quando os deuses mais primeiros, os que fizeram o mundo, estavam ainda vagando pela noite, se conta dos deuses que eram o I'kal e o Votán. Dois eram de um só. (EZLN, 1995, p. 159- 160 - tradução nossa).

Na narrativa do Velho Antônio, emerge aos olhos mestiços do Subcomandante Insurgente Marcos a parábola dos deuses Ik'al e Votán, que encontramos no Popol Wuj: "Um era luz como manhã de maio no rio. O outro era escuro, como noite de frio e caverna. Eram o mesmo. Era uno os dois, porque um fazia ao outro" (SUBCOMANDANTE..., 2011, p. 52 - tradução nossa). Da mesma parábola, o Velho Antônio o ensina sobre a criação do dia e da noite, assim como sobre o aprender a caminhar perguntando, este considerado um dos princípios centrais do Zapatismo, na construção de seu projeto autonômico.

O Velho Antônio ensina ao Subcomandante Insurgente Marcos o mito do Votán Zapata, isto é, a união de Ik'al e Votán em um só deus, o Votán Zapata, que representa o caminhar juntos e a escolha pelo caminho longo (que remete ao calendário maia da Cuenta Larga), portando consigo a memória histórica dos povos originários maias. Para o Subcomandante Insurgente Marcos, o mito do Votán Zapata constituiu o primeiro grande ensinamento do Velho Antônio, o aprendizado dos saberes da cosmovisão maia e, sobretudo, de como conceber a resistência, a rebeldia e a luta 
por dignidade e autonomia desde outros referentes vinculados a uma história milenária, à história dos povos maias. O Votán Zapata expressa uma luta política que une o horizonte utópico dos guerrilheiros que chegaram à Selva Lacandona com a utopia própria das comunidades maias que ali habitavam e que também se encontravam em resistência ao final do século XX (BARBOSA, 2015).

Outros espaços da ação política do Zapatismo recuperam a dimensão epistêmica do Popol Wuj, com o objetivo de fortalecer a identidade maia e, concomitantemente, consolidar o processo formativo do sujeito histórico-político zapatista. Em 2003, com a criação dos Caracóis e das Juntas de Bom Governo, ${ }^{12}$ o Movimento Zapatista reordena seu território e consolida seu projeto autonômico. Os Caracóis constituem as sedes das zonas dos territórios rebeldes e autônomos zapatistas, centros regionais administrativos e logísticos, responsáveis por organizar as atividades internas e externas do conjunto dos Conselhos Autônomos dos Municípios Autônomos Rebeldes Zapatistas (MAREZ). ${ }^{13}$

Encontramos a simbologia do caracol nos códices maias, nos sacrifícios rendidos aos deuses, nos ritos de puberdade, assim como nos de fecundação, parto e nascimento, uma vez que é símbolo da deusa lunar Ixchel, deidade da procriação, do matrimônio, da medicina, das águas e da terra. A denominação dos territórios zapatistas com o nome de Caracol vincula-se à concepção cíclica do tempo em contraposição à visão linear da história. O caracol também é um instrumento usado para convocar as assembleias comunitárias, isto é, um convite ao diálogo coletivo e à participação ativa da comunidade na vida comunitária. Para os anciãos, representa sair de sua interioridade para adentrar ao coração do outro, ou seja, a comunicação dialógica que se estabelece em um caminho em espiral, em um movimento contínuo

12 As Juntas de Bom Governo constituem os centros administrativos do Caracol. Está representada por um ou dois membros dos Conselhos Autônomos dos Municípios Autônomos Rebeldes Zapatistas (MAREZ) e são escolhidos pela assembleia.

13 Cada Caracol possui uma determinada quantidade de MAREZ e cada MAREZ está composto por uma quantidade de comunidades pertencentes às comunidades indígenas de diferentes etnias maias. 
endógeno e exógeno. Do mesmo modo, representa o caminhar lento do caracol, que simboliza o processo de construção dos canais de comunicação, diálogo e debate articulado entre as comunidades zapatistas até chegar a um consenso.

A narrativa política zapatista incorpora uma leitura epistêmica do Popol Wuj na reivindicação dos seus direitos como povos indígenas e na defesa de seus territórios e dos bens naturais neles existentes. No projeto político da autonomia, almeja-se recuperar a relação ancestral com seus territórios, no reconhecimento da herança milenária dos povos maias que se reconfigura na luta por dignidade, liberdade e justiça. Para o Zapatismo, recuperar sua identidade sociocultural faz parte do processo de descolonização e para a consolidação de outro paradigma onto-epistêmico, em que os povos originários alcancem a emancipação humana a partir da superação de uma condição histórica de subordinação colonial, patriarcal e de expropriação territorial.

O Popol Wuj também é incorporado aos processos educativos do Sistema Educativo Rebelde Autônomo Zapatista de Libertação Nacional (SERAZLN), ${ }^{14}$ ao ser trabalhado pedagogicamente no âmbito das Escolas Autônomas Zapatistas, sobretudo na área de história e das línguas. No livro didático Arte en Rebeldía (EZLN, 2006), podemos ver a citação do Popol Wuj, ao fazer referência à criação dos homens, presente no tema Historia del Arte:

Eis aqui, pois, o princípio de quando se dispôs a fazer o homem e quando se procurou o que deveria entrar na carne do homem. E disseram os Progenitores, os Criadores e os Formadores "(...) que apareça o homem, a humanidade, sobre a superfície da terra". Assim disseram. E assim encontraram a comida e esta foi a que entrou na carne do homem criado, do homem formado: este foi seu sangue, deste se fez o sangue do homem. Assim entrou o milho [na formação do homem] por obra dos Progenitores (EZLN, 2006, p. 88 tradução nossa).

14 Para um aprofundamento do SERAZLN, consultar Barbosa (2015). 
A expressão estética do mito criador - os homens e as mulheres do milho - está enraizada na práxis política do Zapatismo. Além do recurso literário do Popol Wuj utilizado nas escolas autónomas, os murais existentes nos Caracóis e nas comunidades, bem como os bordados feitos pelas mulheres zapatistas constituem a maior expressão desse mito. É comum encontrarmos murais com pinturas de espigas de milho, em que cada grão possui um rosto zapatista, com um passa-montanhas.

Alguns murais reportam à herança histórica dos povos maias, como o que adorna a Escola Primária Rebelde Autônoma Zapatista, da comunidade de Jerusalén, no Caracol IV - Morelia. Esse mural se refere à vida cultural de Toniná, antiga cidade maia, e nele estão os utensílios para o plantio e a colheita, bem como o trabalho coletivo realizado nessa cidade. Os promotores de educação afirmam que:

Acreditamos ser importante resgatar a história de nossos antepassados. Eles sabiam se organizar bem, trabalhavam em coletivo, tinham seus próprios remédios, sua própria educação, como se podia trabalhar a natureza, e por isso é importante conhece-los. Por isso no mural se pintam, e por isso nós, homens e mulheres, também estamos nos organizando no trabalho coletivo: nos murais, na produção do feijão e do milho, resgatando nossas plantas medicinais, a saúde e a educação (EZLN, 2006, p. 225 - tradução nossa).

No dia 21 de dezembro de 2012, os zapatistas realizaram a Marcha do Silêncio, dia em que 40 mil bases de apoio zapatista marcharam, em silêncio e com seus passa-montanhas, em todas as cidades em que realizaram o alçamento armado em $1994 .{ }^{15} \mathrm{~A}$ data alude ao Oxlajuj B'aqtun ou Baktun, fechamento de um ciclo de 394 anos no calendário maia. Nesse mesmo dia, o Comitê Clandestino Revolucionário - Comandância Geral do EZLN - emitiu o seguinte comunicado: ${ }^{16}$

15 Nessa data se anunciava, especulativamente, o "fim do mundo".

16 O comunicado foi gravado e seu áudio foi disponibilizado no sítio do Enlace Zapatista. Disponível em: <http://enlacezapatista.ezln.org.mx/2012/12/21/ comunicado-del-comite-clandestino-revolucionario-indigena-comandanciageneral-del-ejercito-zapatista-de-liberacion-nacional-del-21-de-diciembre-del2012/>. Acesso em: 01 ago. 2019. 


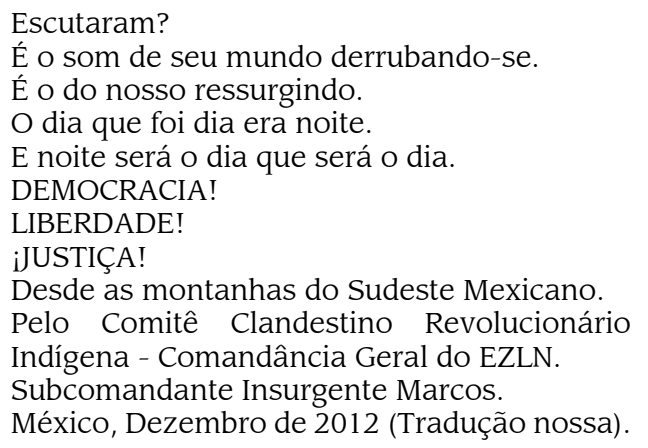

Além dos zapatistas no México, podemos ver a apropriação do Popol Wuj em outras organizações e movimentos maias, a exemplo do Movimento de Resistência Político-Cultural Maia da Guatemala. O Movimento de Resistência Político-Cultural constitui um processo histórico de conformação de uma plataforma político-ideológica, impulsionada nos últimos quarenta anos por intelectuais e organizações maias, com o objetivo de recuperar sua identidade cultural, articulada aos processos políticos de defesa territorial, dos direitos humanos e comunitários, no enfrentamento do projeto de ladinização, bem como na denúncia da histórica violência epistêmica, militar e estrutural do Estado, herança colonial da história guatemalteca (BASTOS; CAMUS, 2003; ALMAGUER, 2015).

Ao longo desse período, o Movimento de Resistência PolíticoCultural tem elaborado uma série de documentos, ${ }^{17}$ declarações, acordos, pesquisas, práticas culturais e discursivas, que expressam uma reapropriação da identidade cultural maia e o estímulo à descolonização do pensamento e dos corpos, característico da luta dos povos originários na história política contemporânea. Essa coletânea incorpora conteúdos e princípios ético-filosóficos do Popol Wuj como uma estratégia de resistência cultural, ao mesmo tempo em que reconfigura seu discurso político em sua dimensão ontológica e epistêmica, ao problematizar a natureza colonial do

17 Almaguer (2015) desenvolveu um estudo de referência acerca da incidência político-cultural do Popol Wuj, nos documentos elaborados pelo Movimento de Resistência Político-Cultural. Alguns dos documentos citados nesse escrito são aprofundados em sua tese doutoral. 
paradigma moderno ocidental capitalista eurocentrado, enraizado nas relações socioculturais, produtivas e políticas da Guatemala.

A intensificação do processo organizativo e das bases ideológicas do Movimento de Resistência Político-Cultural ocorreu nas décadas de 70 e 80 do século XX, ocasião em que se estabeleceram estratégias de recuperação das línguas maias, de valorização das vestimentas e de seu conteúdo simbólico, das cerimonias tradicionais, da cosmogonia e da própria história da civilização maia (MOSQUEDA, 2014; ALMAGUER, 2015). Nesse contexto, foram centrais as traduções do Popol Wuj realizadas por intelectuais maias ${ }^{18}$ de caráter mais minucioso e fidedigno aos elementos epistêmicos da cosmovisão e da cosmogonia maias. Outro espaço fundamental inaugurado nesse período foram os congressos articulados por intelectuais maias, com o objetivo de aprofundar o estudo analítico do Popol Wuj.

Em 2010, por exemplo, realizaram na Guatemala o V Congresso Internacional sobre o Po (ol) Wuj: reencontro com o conhecimento dos nossos ancestrais, Q'uma'r Ka'aj e as artes frente ao novo $B a^{\prime} q t u n$. Naquela ocasião, debateram seu posicionamento teórico-político nas seguintes áreas: 1. Sistema educativo nacional e conhecimento maia; 2. O Popol Wuj e a educação bilíngue cultural; 3. Povos originários e participação política: uma interpretação a partir do Popol Wuj; 4. Q'uma'r Ka'aj ${ }^{19}$ e o anteprojeto de lei de lugares sagrados; 5. Perspectivas das autoridades ancestrais em relação aos lugares sagrados (ALMAGUER, 2015).

É válido destacarmos a transcendência do Q'uma'r $K a^{\prime} a j$, na memória histórica da luta contemporânea dos povos maias da Guatemala, sobretudo por ter sido sede principal e centro político dos k'iche' e das cinco gerações de Ajpop'ib'do. Além disso, a cidade foi o cenário de embates políticos com os espanhóis, além de ter um templo dedicado a Tojil, deidade dos maias $k^{\prime} i c h e^{\prime}$ (ALMAGUER, 2015).

18 Vide nota de rodapé 7.

19 Q'uma'r Ka'aj é a cidade fundada pelos ancestrais dos povos $k^{\prime} i c h e^{\prime}$, hoje um sítio tombado como patrimônio arqueológico da humanidade. 
Alguns dos documentos elaborados, que se inspiram ou apresentam trechos do Popol Wuj, são:

- Declaração de Iximche': de fevereiro de 1980, teve por objetivo denunciar, junto à Embaixada da Espanha, o massacre de indígenas ixiles e k'ich'e durante a conquista. Esta declaração fala da violência e massacre permanentes em toda a história política da Guatemala e constitui o primeiro pronunciamento público, de caráter nacional, em que uma diversidade de organizações se posiciona como povos indígenas e maias (MACLEOD, 2011). Consideramos essa declaração um documento político fundamental para os maias, por denunciar o histórico despojo de seus territórios, perpetuado por um padrão de dominação de caráter colonial e racista, assentado na violação de direitos humanos dos povos originários da Guatemala;

- Declaração de Atitlán: de 2002, pelo direito à alimentação dos povos indígenas. O documento enfatiza o direito ancestral coletivo de autodeterminação dos povos originários, bem como o direito sobre a terra, a água e o território;

- Declaração política resultante do Primeiro Congresso Nacional do Povo Maia, em 2003, cuja data de realização levou em consideração a contagem do tempo conforme o calendário maia. Nessa declaração política, encontramos:

Autoridades, delegados e delegadas de diversas comunidades e organizações maias da Guatemala, reunidos os dias Lajuj Kej y Junlajuj Q'anil do ano Kaji' E', (18 e 19 de agosto de 2003) em virtude de ter sido convocados pela Comissão Consultiva Maia para a institucionalização do Ente de Consulta, que denominamos Assembleia Nacional de Representantes do Povo Maia. Com a permissão dos nossos Criadores e Formadores, mães e pais da vida, dos nossos ancestrais, e mártires caídos durante o transcurso de nossa história na luta constante para a reivindicação e dignificação do nosso povo. No diálogo, consulta e acordo construímos e tecemos a mais de dois anos consecutivos este Ente de Consulta, porque vivemos, vimos e 
sentimos a necessidade de que juntos sigamos semeando e fortalecendo a semente da existência do povo Maia (DECLARACIÓN..., 2003, [s.p.] - tradução nossa).

- Declaração de Iximche'-Tecpan, resultante da III Cumbre Continental dos Povos e Nacionalidades Indígenas do Abya Ayala, realizada em 2007, com datas determinadas pelo calendário maia.

- Documento resultante do $8^{\circ}$ Encontro Continental de Guias Espirituais Indígenas Kam B'alam el Cóndor y el Águila, realizado em 2010, em Iximche':

Em harmonia com nosso Criador e Formador, com a permissão de nossos Avôs e Avós, com alegria em nosso espírito e em nossa mente e com a vontade de transmitir umas palavras de bem-estar à humanidade; guias espirituais, autoridades e líderes indígenas do continente de Abya Yala, nos reunimos na Cidade Maia Sagrada de IXIMCHE na Guatemala, para refletir sobre todas as formas de vida: humana, animal, vegetal e mineral: desde a cosmovisão dos nossos Povos, para gerar sábios conselhos que orientem nossas ações, para um bem-estar e dignidade de todos os Povos do Mundo (KAJKAN, 2010, [s.p.] - tradução nossa).

- Declaração política Hacia un tiempo de grandes cambios, de 11 de novembro de 2012, emitida pelo conselho político do 13 Baktun: a declaração apresenta a necessidade de superação de uma história de medo e destruição vivida pelos povos maias na Guatemala, ao longo de onze baktunes. Também faz referência ao encerramento de um baktun de resistências, lutas e rebeliões para a abertura de um novo Baktun ou início de uma nova era em defesa dos direitos dos povos maias (CONSEJO..., 2012).

Em outubro de 2011, é lançado o documentário Corazón del Cielo, Corazón de la Tierra, que acompanha a vida cotidiana, as cerimônias e as diferentes formas de resistência de seis jovens do México e da Guatemala. O documentário mescla trechos do Popol 
Wuj com narrativas políticas, entre elas a do Movimento Zapatista. O documentário foi lançado internacionalmente em 2012, em 100 festivais de cinema, e recebeu 15 premiações. Em 2006, em Santiago, no Chile, foi produzido um curta-metragem animado que conta a história da criação do Popol Wuj, destinado ao público infantil (POPOL..., 2006). Ambas as produções evidenciam que o Popol Wuj continua sendo um referente importante para entender a história sociocultural e política da América Central.

\section{Considerações finais}

conforme apresentamos, os escritos maias pré-hispânicos são uma antologia essencial para conhecermos o legado do pensamento filosófico, espiritual, sociocultural e científico da antiga civilização maia. Apesar da destruição da quase totalidade dos registros escritos pelos espanhóis e dos séculos de desconhecimento daqueles que foram quase que milagrosamente recuperados, contamos com fontes primárias documentais que permitem e permitirão o aprofundamento científico no âmbito da historiografia indígena mesoamericana.

É surpreendente identificarmos a vitalidade da dimensão epistêmica dessas obras na contemporânea luta política dos povos originários, o que revela o potencial de uma cultura milenária, de uma cosmogonia e de uma cosmovisão que se mantêm firmes no incessante processo de descolonização e na reafirmação de outros paradigmas para pensarmos a nós mesmos e à natureza em sua totalidade vital.

A maneira como o Popol Wuj tem sido apropriado e difundido como legado histórico, estético e político expressa a conjugação de diferentes elementos na recuperação e fortalecimento da identidade sociocultural dos povos originários da região mesoamericana e na conformação de um sujeito histórico-político. Nesse processo, o Popol Wuj cobra vitalidade como relicário de uma memória coletiva resguardada na tradição oral, repassada milenariamente nos ritos e em outras práticas culturais.

Da apreensão do Popol Wuj, emergem algumas matrizes epistêmicas, relacionadas à configuração de uma resistência linguística, 
expressa na valorização das línguas maias e na sua relação com a afirmação de outra racionalidade, outra episteme, que determina uma forma de ser-estar-pensar e posicionar-se desde e com o mundo. Igualmente, o livro permeia o processo de apropriação do tempo e do espaço em consonância com o sistema calendárico maia, um referente que nutre a sociabilidade comunitária, mas também a agenda política, a produção teórico-analítica e os tempos da resistência, da rebeldia e da luta indígena na América Central.

Certamente o livro Popol Wuj constitui um referente pedagógico e político fundamental no pluralismo próprio dos povos originários maias, em nossa contemporaneidade, com uma ressonância que ultrapassa as fronteiras da Guatemala e do México, ao proporcionar um olhar dialógico e dialético com outras culturas e resistências políticas da América Latina.

\section{REFERÊNCIAS}

AlMAgueR, R. X. R. El Popol Wuj y sus traducciones por mayahablantes: memoria histórica y resistencia cultural en Guatemala, 1970-2014. 2015. 286f. Tese (Doutorado em Historiografia) -- Programa de Posgrado en Historiografía, Universidad Autónoma Metropolitana, Cidade do México, 2015.

ALVARADO, C. C. et. al. Q'ij Alaxik: La importancia de desarrollar nuestras vocaciones para tener bienestar mental y una convivencia armónica con los demás. Cidade de Guatemala: Médicos Descalzos, 2013.

BARBOSA, L. P. Educación, resistencia y movimientos sociales: la praxis educativo-política de los Sin Tierra y los Zapatistas. Cidade do México: LIBRUNAM, 2015.

BASTOS, S.; CAMUS, M. El movimiento maya en perspectiva. Cidade de Guatemala: FLACSO, 2003.

COBIÁN, D. L. Génesis y evolución de la figura femenina en el Popol Vuh. CIdade do México: Plaza y Valdés, 1999.

COLOP, E. S. Popol Wuj. Cidade de Guatemala: Cholsamaj, 2008.

CONSEJO Político 13 Baktun. Declaración del Consejo Político 13 Baktun: hacia un tiempo de grandes cambios. Iximulew, Guatemala: [s.n.], 2012. Disponível em: <https://www.alainet.org/images/GT\%2013\%20 baktun\%20hacia\%20un\%20tiempo\%20de\%20grandes\%20cambios(1).pdf>. Acesso em: 30 jul. 2019. 
DECLARACIÓN Política: primer congreso nacional del pueblo maya. América Latina en Movimiento, [on line], 19 ago. 2003. Guatemala. Disponível em: <https://www.alainet.org/es/active/4433>. Acesso em: 30 jul. 2019.

DE LA GARZA, M. El legado escrito de los mayas. Cidade do México: Fondo de Cultura Económica, 2012.

DE VOS, J. Una tierra para sembrar sueños: historia reciente de la Selva Lacandona. 1950-2000. Cidade do México: Fondo de Cultura Económica / CIESAS: 2002.

EZLN - Exército Zapatista de Libertação Nacional. La historia de las preguntas: documentos y comunicados. v. 2. Cidade do México: ERA, 1995.

Arte en Rebeldía. Cidade do México: Ediciones Rebeldía, 2006.

KAJKAN, F. Reflexionando sobre la vida desde nuestros conocimientos tradicionales y saberes propios. In: Encuentro Continental de Guías Espirituales Indígenas Kan B'alam, el condor y el águila, 8., Iximche, Guatemala. Anais..., Iximche, 22 set. 2010. Disponível em: <http:// lacasadelaguila.blogspot.com/2010/10/viii-encuentro-continental-deguias.html>. Acesso em: 30 jul. 2019.

MACLEOD, M. iQue todos se levanten! Rebelión indígena y la Declaración de Ixinché. In: CASTAÑEDA, M. E. V. (coord.). Guatemala, la infinita historia de las resistencias. Cidade de Guatemala: Secretaría de la Paz de la Presidencia de la República, 2011. p. 439 - 479.

MARIÓN, M. O. Identidad y ritualidad entre los mayas. Cidade do México: INI, 1994. 1999.

El poder de las hijas de luna. Cidade do México: Plaza y Valdés,

MOSQUEDA, Z. M. De la resistencia a la revitalización de la narrativa maya contemporánea. 2014. 245f. Tese (Doutorado em Filosofia) Hispanic Cultural Studies, Michigan State University, Michigan, 2014.

NAVARRO, F. Prólogo. In: SUBCOMANDANTE Insurgente Marcos. Relatos del Viejo Antonio. Cidade do México: Ediciones Rebeldía, 2011. p. 03 - 17. POPOL Vuh Animado. Produção: Ana María Pavez. Ilustração: Paloma Valdivia. Animação: Carlos Munita. Locução: Antonio Rosset. Santiago de Chile: [s.n.], 2006. 1 video (11 min), color., son. Disponível em: <https:// www.youtube.com/watch?V=AKZCLYxchIE>. Acesso em: 30 jul. 2019.

RECINOS, A. Popol-Vuh: las antiguas historias del Quiché. Cidade de Guatemala: Piedra Santa, 1982. 
SANTOS, L. E. S.; VALVERDE, M. del C. Historiografía maya de origen indígena (siglos XVI-XIX). In: GALVÁN, J. R. R. (org.). Historiografía mexicana: historiografía novohispana de tradición indígena. v. I. Cidade do México: UNAM, 2003.

SLAVIERO, M. E. C. El arte verbal k'iche': las funciones poéticas de los textos rituales mayas contemporáneos. Cidade do México: Praxis, 2004.

El Popol Vuh y su función poética: análisis literario y estudio crítico del texto k'iche'. 2007. 761f. Tese (Doutorado em Estudios Mezoamericanos) - Universidad Nacional Autónoma de México, Cidade do México, 2007.

SUBCOMANDANTE Insurgente Marcos. Relatos del Viejo Antonio. Cidade do México: Ediciones Rebeldía, 2011.

VILLACORTA, A.; RODAS, F. Manuscritos de Chichicastenango - El Popol Buj: estudio sobre las antiguas tradiciones del pueblo Quiché. Cidade de Guatemala: Sánchez \& De Guise, 1927. 